\title{
The Colon Cutoff Sign: The Internist's Perspective on Diagnosing Acute Pancreatitis
}

\author{
Anthony Sandre, MD, MSc and Ameen Patel, MB, FRCP(C), FACP
}

\begin{abstract}
About the Authors
Anthony Sandre, MD, MSc, is a Resident Physician, Internal Medicine Residency Program, McMaster University.

Ameen Patel, MB, FRCP (C), FACP, is a Professor, Department of Medicine, McMaster University.

Corresponding Author: anthony.sandre@medportal.ca

Submitted: September 30, 2019. Accepted: December 4, 2019. Published: August 27, 2020. DOI: 10.22374/cjgim.v15i3.397
\end{abstract}

\begin{abstract}
The colon cutoff sign is a radiographic sign often associated with a diagnosis of acute pancreatitis. The patient highlighted in this case presented with nausea, vomiting, and abdominal discomfort and was referred with a diagnosis of viral gastroenteritis. The abdominal radiograph demonstrated the colon cutoff sign, but all other biochemical and imaging modalities were within normal limits. This case highlights the importance of relying on the entire clinical assessment when diagnosing pathology.
\end{abstract}

\begin{abstract}
Resume
Le signe de coupure du côlon est un signe radiographique souvent associé à un diagnostic de pancréatite aiguë. Le patient mis en évidence dans ce cas présentait des nausées, des vomissements et une gêne abdominale et a été orienté vers un service de gastro-entérite virale. La radiographie abdominale a montré le signe de coupure du côlon, mais toutes les autres modalités biochimiques et d'imagerie étaient dans les limites normales. Ce cas souligne l'importance de s'appuyer sur l'ensemble de lévaluation clinique pour diagnostiquer la pathologie.
\end{abstract}

A 65-year-old male presented to our hospital for evaluation of nausea, vomiting, and abdominal pain. The patient's past medical history was notable for alcohol abuse, peptic ulcer disease, and coronary artery disease. Physical exam demonstrated diffuse tenderness in the right and left upper abdominal quadrants. Electrolytes and serum lipase were within normal limits. An abdominal radiograph (Figure 1) demonstrated the "colon cutoff" sign concerning for acute pancreatitis. An abdominal ultrasound was normal. Despite diagnostic imaging suggesting otherwise, the patient was diagnosed with viral gastroenteritis and discharged following supportive care.

The colon cutoff sign is a radiographic sign, originally described in abdominal radiographs, indicating the absence of gas in the colon distal to the splenic flexure.1,2 The colon cutoff sign represents functional paralysis of the descending colon secondary to pancreatic inflammation. Beyond case reports, there is a paucity of published data on the sensitivity and specificity of this sign. One retrospective chart review reported a sensitivity of 56\%.3 Specificity was not reported. Although an elevation in serum lipase is not necessarily specific, the sensitivity and specificity for elevation of this biomarker have been reported as $85-100 \% .4$ The sensitivity and specificity of abdominal ultrasound for the diagnosis of acute gallstone pancreatitis is reported as $71 \%$ and $98 \%$, respectively. 5 In this case, the colon cutoff radiographic sign was inconsistent with a biochemical diagnosis of pancreatitis. In the setting of an abdominal radiograph showing the colon 


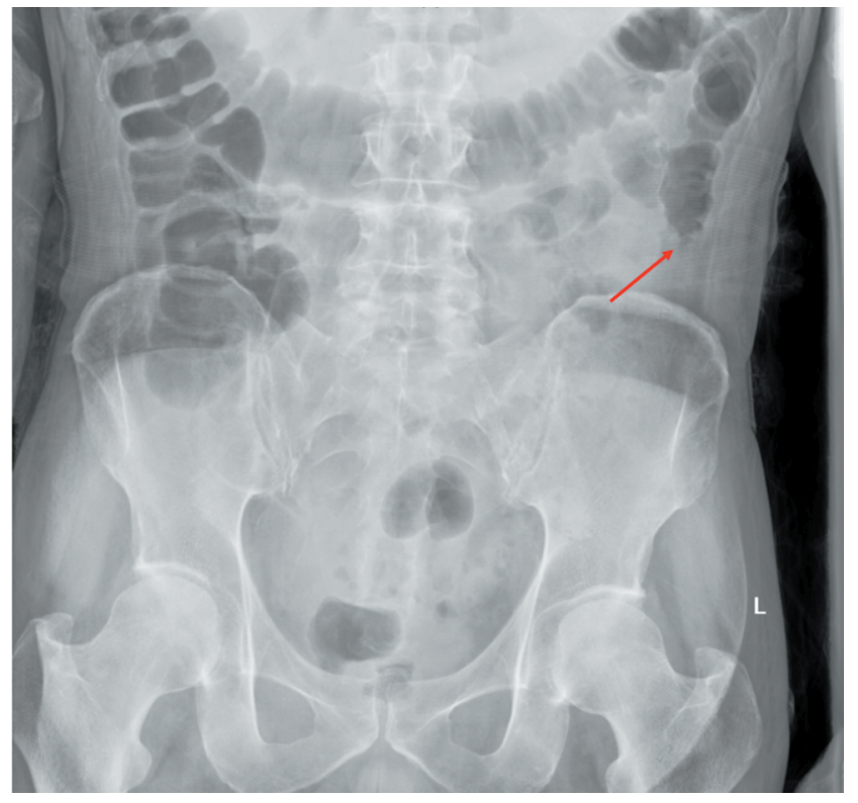

Figure 1. Abdominal radiograph demonstrating the "colon cutoff" sign, indicated with a red arrow. cutoff sign, clinicians should rule-out other intra-abdominal pathology, including, but not limited to, viral infections, colon cancer, inflammatory bowel disease, mesenteric ischemia, and urinary and biliary pathology. This case illustrates the importance of assessing all available data and placing appropriate strength on each investigation based upon its test characteristics in the diagnostic reasoning process.

\section{Conflict of interest}

None.

\section{Sources of Funding}

None.

\section{References}

1. Cantwell DF, Pollock A V. Radiology of acute pancreatitis. J Fac Radiol 1959;10(2):95-99. doi:10.1016/S0368-2242(59)80069-5

2. Pickhardt PJ. The colon cutoff sign. Radiology 2000;215(2):387-89. doi:10.1148/radiology.215.2.r00ma18387

3. Brascho DJ, Reynolds TN, Zanca P. The radiographic "colon cut-off sign" in acute pancreatitis. Radiology 1962;79(November):763-69. 